\title{
The investigation of renal disease using radionuclides
}

\author{
Harold L. AtKins \\ M.D. \\ Medical Department, \\ Brookhaven National Laboratory \\ Upton, New York 11973
}

\author{
Leonard M. Freeman \\ M.D. \\ Section of Nuclear Medicine, \\ Department of Radiology, \\ Albert Einstein College of Medicine, \\ 1300 Morris Park Avenue, \\ Bronx, New York 10461
}

\begin{abstract}
Summary
The use of radioactive labels for tracers is an important part of the investigation of renal disease. These techniques seldom replace, but often complement radiographic techniques. Generally, the radionuclide methods provide functional and dynamic information in a non-invasive, non-traumatic type of examination. The examinations usually are relatively simple to perform and carry a very low risk of untoward reaction.

The past decade has seen significant advances in radiopharmaceutical design and instrumentation. It is expected that the next decade will produce an even greater advance in this field.
\end{abstract}

\section{Introduction}

The phenomenal growth in the field of Nuclear Medicine over the past decade has brought with it significant advances in methods and materials for the investigation of disease states involving the kidney. Despite the greater anatomical detail provided by intravenous pyelography and renal arteriography, radionuclide techniques remain attractive for several reasons: (1) they provide physiological and functional information not always attained through radiographic means; (2) frequently the data so obtained may be quantified; (3) the methods are non-invasive and carry a much lesser risk of morbidity. The examination using radionuclides should be considered as complementary to, and not competitive with, radiographic techniques, particularly in the investigation of renal hypertension.

Several recent reviews and published proceedings of conferences are available to provide detailed information regarding specific methodologies and clincical applications (Blaufox \& F. Brentano, 1972; Symposium, 1969, 1971; Blaufox, 1972). This review will concentrate on the advances in instrumentation, radiopharmaceuticals and practical clinical applications in the past decade.

\section{Instrumentation}

The development of camera devices has created the possibility of combining radionuclide imaging with dynamic studies. This has opened up a whole new area of clinical applications. The rectilinear scanner is rapidly being displaced as the 'workhorse' instrument in nuclear medical facilities by cameras as the spatial resolution and data-handling capabilities of the latter have improved. Even simple single and dual probe scintillation detectors have begun to fall in disuse as the radionuclide camera takes over more and more of the clinical load.

The most common stationary imaging device is the Anger-type scintillation camera with a single thin crystal and an array of nineteen photomultiplier tubes. A detailed description will not be offered here but is available elsewhere (Anger, 1967). In some recently available commercial models the crystal size has increased from $10^{\prime \prime}$ to $12^{\prime \prime}$ in diameter, which is rather useful for renal studies. The possibility of electronically splitting the crystal in order to record separately the data from both halves of the field was a useful early innovation for performing renography (Harbert, Ashburn \& Davidson, 1968). As one might expect, the considerable background activity included in the field of view proved to be a major disadvantage of this method. This is now being supplanted by accessories such as multichannel analyzers and computers which enable one to process data more readily and allowing for more accurate localization of areas of interest and for digitization of data.

The Bender autofluoroscope is a multicrystal array with a built-in system for flagging areas of interest, strip chart read-out of curves from these areas and magnetic tape storage of data (Bender, 1964). For dynamic processes it has poorer spatial resolution than the Anger-type camera, although recent innovations have resulted in significant improvement in static imaging.

Errors in renography derived from improper place- 
ment of the probe are no longer a problem when scintigraphy is associated with the study. Accurate flagging of the renal area and separation of cortex from medulla are possible (zum Winkel et al., 1972). Background can be nearly eliminated thus improving the quality of the examination. When imaging is available it is possible to recognize infundibular, uretero-pelvic or ureteral obstruction and delineate delayed renal transit of radioisotope.

Rapid sequential imaging is also useful with appropriate radiopharmaceuticals for assessing vascularity of the kidneys in such problems as trauma, embolic disease, space-occupying lesions and transplantation of the kidney (Black, King \& Smith, 1968; Freeman et al., 1969b; Rosenthall, 1966). Storage on magnetic tape is especially useful in this type of study.

The computer is playing an ever enlarging role in manipulation of images and data analysis. A number of dedicated systems are now available for interfacing with scintillation cameras. Detailed analysis of the renogram curve by means of computer is being attempted by a number of investigators (Turco, Ghemi \& Segre, 1967; Britton \& Brown, 1971; Hirakawa, Kuwahara \& Ueyama, 1972). While not routinely in use clinically these methods are providing further insight into the physiological processes involved.

\section{Radiopharmaceuticals}

A number of new radiopharmaceuticals has been developed in recent years which can be applied to the investigation of renal disease. Many of these complement the scintillation camera development in making possible rapid dynamic imaging.

${ }^{197} \mathrm{Hg}$ has largely replaced ${ }^{203} \mathrm{Hg}$ as a label for chlormerodrin. The shorter half-life of 2.7 days and the $77 \mathrm{keV}$ gamma energy result in a substantial reduction in renal radiation dose (approx. 1.2 rads/ $100 \mu \mathrm{Ci}$ ) compared to ${ }^{203} \mathrm{Hg}$ (approx. $10 \mathrm{rads} / 100$ $\mu \mathrm{Ci})$ (McAfee, 1970). The photon energy is somewhat below the optimal for use with the gamma camera and a large percentage of the scattered radiation is within the photopeak making its exclusion difficult. ${ }^{197} \mathrm{Hg}$ chlormerodrin has been useful in localizing the kidneys for renography, as an agent for the chlormerodrin uptake test and for initial static imaging of the kidneys prior to dynamic 'flow' studies; particularly in the investigation of spaceoccupying lesions or in renal vascular disease.

One of the major factors in the expansion of Nuclear Medicine in the past decade has been the development of ${ }^{99} \mathrm{~m}$ technetium ( $T \frac{1}{2}$ of $6 \mathrm{hr}$, gamma energy $140 \mathrm{keV}$ ), as a label for multiple uses in the form of a variety of tagged compounds. As sodium pertechnetate, ${ }^{99 \mathrm{~m}} \mathrm{Tc}$ has been useful in the evaluation of the integrity of vascular flow to the kidneys and in the differentiation of vascular (tumour) andœ non-vascular (cyst) lesions.

Other compounds of ${ }^{99 \mathrm{~m}} \mathrm{Tc}$ have been devised for $\stackrel{\mathrm{D}}{\stackrel{2}{2}}$ specific applications to renal problems. Among these.. have been technetium iron ascorbate (Harper et al., $\vec{\Rightarrow}$ 1966), technetium caseidin (Lin et al., 1972) technetium gelatin (Lebowitz, 1971), and technetium? DTPA (Hauser et al., 1970). Only the iron ascorbate $\frac{\overline{\bar{N}}}{\overline{\mathrm{N}}}$ and DTPA are in clinical use at this time. The $\frac{\sqrt{\sigma}}{\widetilde{\sigma}}$ advantages of the technetium label are excellento collimation, low radiation dose, and the possibilitye of administering large quantities of activity for rapid imaging. The technetium iron ascorbate compound:selectively concentrates in the renal cortex and can be $\vec{\omega}$ utilized in a manner similar to ${ }^{197} \mathrm{Hg}$ chlormerodrin ${ }^{\circ}$ to estimate the relative fraction of effective renalo plasma flow to each kidney (Gottschalk, 1967). Approximately $8 \%$ of the administered dose is local- $\overrightarrow{0}$ ized to the renal cortex and most of the remainderir excreted in the urine rather rapidly. Imaging is bestcw performed 2-4 hr after administration when most of the activity which will be excreted has already passed ${ }^{\omega}$ beyond the renal pelvis. Imaging at earlier times willo show confusing 'hot' areas in the upper collecting ${ }_{c}^{-}$ system (Fig. 1). The radiation dose is much lower $\underset{<}{\varrho}$

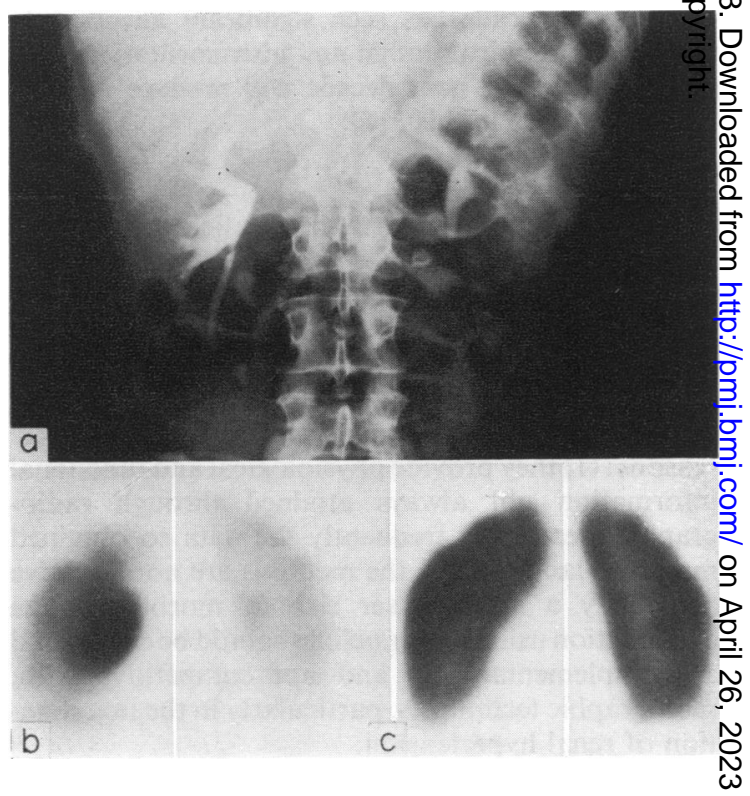

FIG. 1. Use of ${ }^{90 \mathrm{~m}} \mathrm{Tc}$ iron ascorbate for renal imaging. (a) The intravenous urogram shows narrowing of the ureter at the ureteropelvic junction, probably due to an aberrant vascular structure. (b) Image obtained at $1 \mathrm{hr}$ after administration of ${ }^{\circ 0 m T c}$ iron ascorbate shows retention of radioactivity in the right renal pelvis. (c) $\mathbf{A}$ $2 \mathrm{hr}$ study (right) shows cortical distribution of radioactivity without retention of activity in the renal pelvis. 
than from the radiomercurials; $0.27 \mathrm{rad} / \mathrm{mCi}$ to the kidneys and $0.008 \mathrm{rad} / \mathrm{mCi}$ to the whole body (Hauser, Atkins \& Richards, 1971).

A variety of agents has been devised for the measurement of glomerular filtration rate. Among these are ${ }^{57} \mathrm{Co}$ cyanocobalamine (Nelp, Wagner \& Reba, 1964), ${ }^{51}$ Cr EDTA (Stacey \& Thorburn, 1966), ${ }^{113 \mathrm{~m} I n}$ DTPA (Reba, Hosain \& Wagner, 1969), ${ }^{169}$ Yb DTPA (Hosain, Reba \& Wagner, 1969) and ${ }^{131}$ I or ${ }^{125}$ I iothalamate (Sigman et al., 1965). One of the more recent radiopharmaceuticals in this line is ${ }^{99 \mathrm{~m}}$ Tc DTPA (Hauser et al., 1970). This would appear to have the greatest promise for several reasons: (1) the agent is readily prepared by a kit method (Eckelman \& Richards, 1970); (2) ${ }^{99} \mathrm{~m}$ technetium is in general use in most Nuclear Medicine units and readily available; (3) physical characteristics are nearly ideal; and (4) the ability to use large quantities of radioactivity enables one to do a multifaceted study including arteriography, renography and measurement of glomerular filtration rate (Fig. 2).

Rubidium has been utilized for measurement of relative renal blood flow because of the high extraction efficiency of the kidney for this analog of potassium (Torrance, Davies \& Clark, 1961). However, the same information can be obtained from more readily available agents with better imaging characteristics (Gottschalk, 1967).

Absolute measurement of renal blood flow has been carried out with radioactive ${ }^{133}$ xenon (Rosen et al., 1968). Unfortunately this requires arterial catheterization and thereby limits widespread clinical utilization. It can most readily be performed in conjunction with renal angiography but requires that appropriate equipment be present in the radiographic suite.

\section{Clinical utilization}

Renography

Following initial enthusiasm for renography the technique fell into relative disuse for a number of years. Recently its use has been revived because of improved instrumentation, a better understanding of physiological factors important to interpretation and, with the advent of renal transplantation an increased clinical requirement for a relatively sensitive and innocuous test of renal function.

As stated above, the ability to include both kidneys in the field of view of one detector and to flag areas of

FIG. 2. Renal imaging and renography with ${ }^{00 \mathrm{~m} T c}$ DTPA. The patient was hypertensive with normal radiohippuran and intravenous urographic studies. (a) 1-3 min. (b) The 8-10 min scintiphoto and (c) renal curves derived from sequential images indicate right ureteropelvic obstruction. This was probably related to the patient's state of hydration at the time of the study.
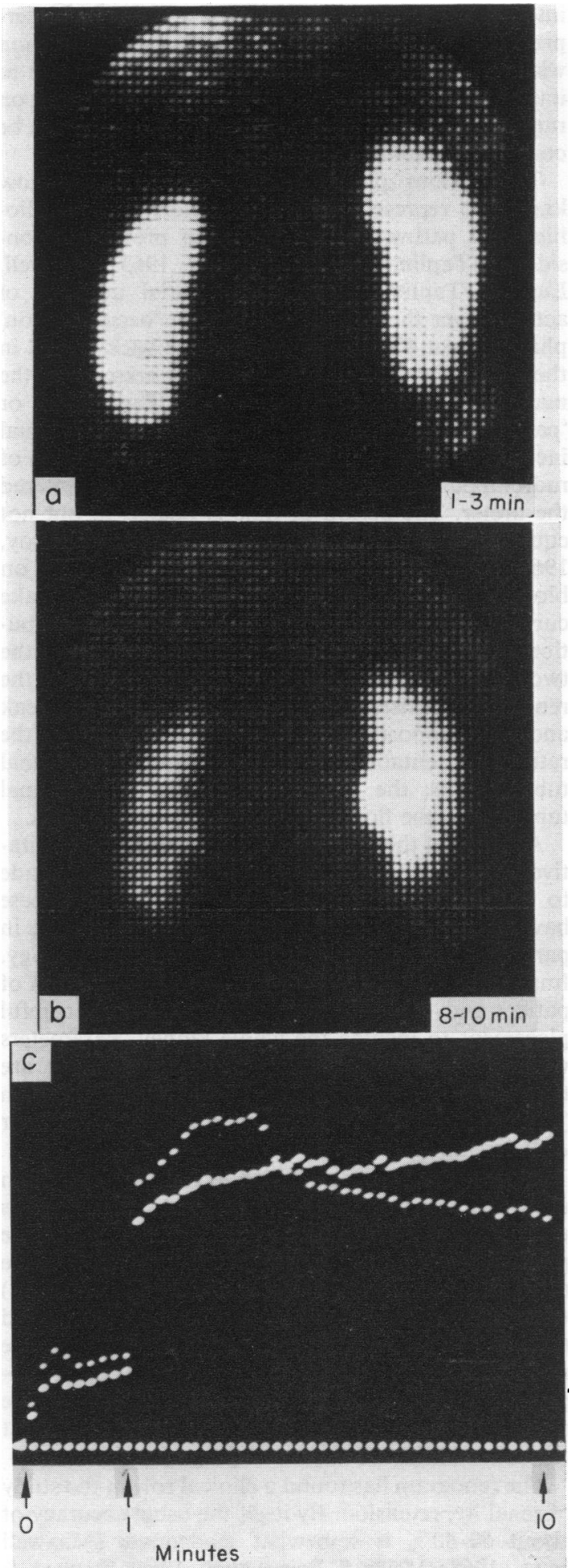
interest has resulted in improved accuracy of interpretation when a camera device is used in conjunction with a system for data manipulation. Errors due to improper placement of probes, wrong scale setting on ratemeters and poor exposure factors for film can be completely avoided.

The various phases of the renogram are now known to represent other parameters of the radiohippuran pathways than had been previously considered (Taplin, Dore \& Johnson, 1963; Maxwell, Lupu \& Taplin, 1968). In the initial upswing of activity over the renal areas (first or 'accumulation' phase) about $40 \%$ is due to vascular background in the flank. The remainder is due to the presence of the material in the renal tubular cells. The second or 'parenchymal' phase consists of a more gradual increase in count rate due to further accumulation of radiohippuran before any radioactivity has entered the ureter. The period of time is related to but not equivalent to the transit time (Blaufox \& Conroy, 1968; Coe \& Burke, 1965). It is highly dependent on blood flow and urine flow. The ratio of the uptake curves in this region is equal to the relative distribution of total effective renal plasma flow between the two kidneys. The third or 'excretory' phase of the renogram consists of the portion following the peak and is a composite of several factors. These are the rate of presentation of radiohippuran to the renal tubular cells, the rate of urine flow in the renal tubules and the flow of urine through the ureters.

Analysis of the renogram has been entirely qualitative in most laboratories. Attempts have been made to be more quantitative in interpretation but these have not generally been very successful. This is due in part to a lack of standardization of methodology. Important factors are state of hydration, position of patient and, when separate probes are used, careful placement to include the whole kidney. Parameters which have been looked at most successfully are time to peak ( $T$ max.) and time to one-half maximum ( $T \frac{1}{2}$ max.) (Kaplowitz, Mitchell \& Blahd, 1965; Meir \& Beierwaltes, 1966).

More recently computerized techniques have been used to improve the quality of the examination as well as to provide data for quantitative analysis. One particularly interesting computer analysis of the renogram is that of Brown \& Britton $(1971,1972)$ who remove the blood background contribution and then separate the components due to renal uptake and excretory function. A number of other approaches are also in use. Although promising, these methods are not within the capabilities of most clinical facilities.

The renogram has found a clinical role in the study of renal hypertension. By itself the usual accuracy of about $60-80 \%$ is somewhat inadequate (Maxwell et al., 1968; Meier \& Beierwaltes, 1966; Stewart \&
Haynie, 1962). However, in conjunction with otheह tests, the renogram can be helpful. Typically, with $\bar{a}$ renal artery stenosis, urine flow in the affected kidnes is slowed due to increased tubular reabsorption. This. results in a flattened curve with a delayed peak (Fig $\overrightarrow{\text { : }}$ 3). Following corrective surgery the renogram study? is useful for assessing the patency of the arterial graft and the restoration of normal function in the kidney $\frac{\overline{\bar{V}}}{\mathrm{C}}$

Other uses of the renogram are in detecting earl rejection phenomena after transplantation, in detec $\propto$ tion of acute tubular or cortical necrosis and inf evaluation of obstructive uropathy. The hippuran 5 output curve described by Brown \& Britton (1972) is obtained by the use of a computer with probes ove $\vec{\omega}$ both kidneys and over the left subclavicular area. As indicated above, corrections are made for bloos background and for clearance of radiohippuran fron? the blood. Where available the technique has beerto
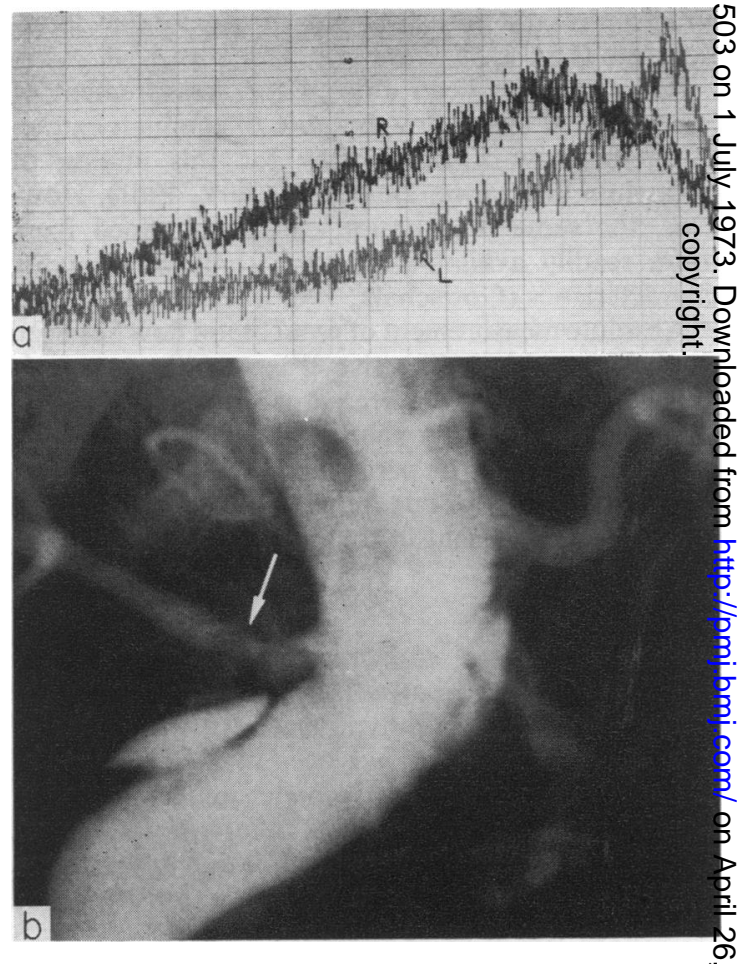

FIG. 3. Hippuran renogram in renal artery stenosis. (a) Conventional dual probe chart recording. The left side shows normal uptake, parenchymal and excretory phases. The right kidney has a much wider peak and delayed slope of excretion. This 'cross-over' pattern is quite typical of unilateral renal disease. The chart recorder was run at a constant speed of $12 \mathrm{in} / \mathrm{hr}$. (b) Aortogram demonstrates stenosis of the main right renal artery (arrowed). Some intravasation of contrast media in the wall of a very tortuous area is present. The left renal artery appears normal. 


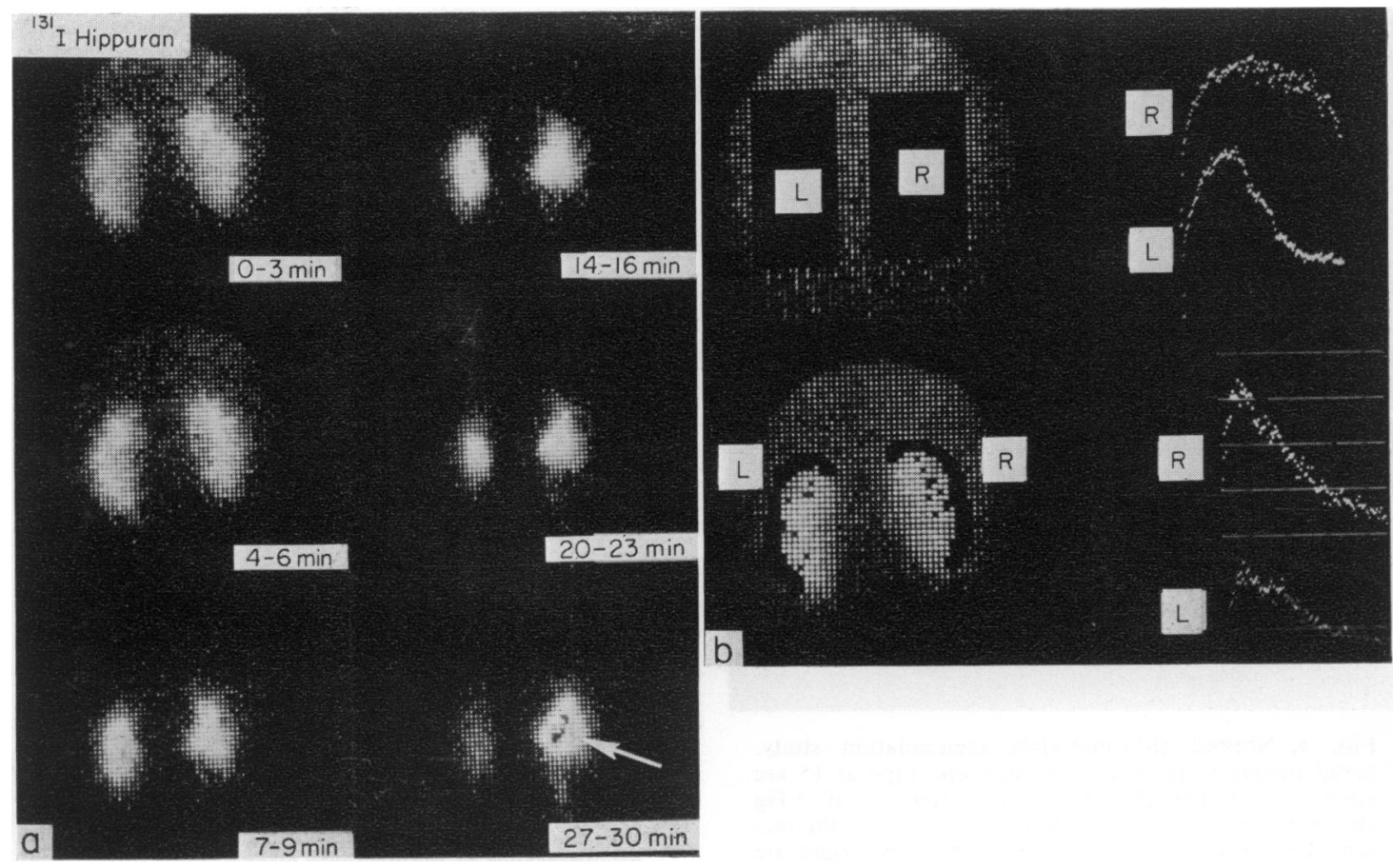

FIG. 4. Hippuran renogram in obstructive uropathy. (a) Serial posterior scintiphotos obtained from a study stored on magnetic tape shows a delay in right-sided excretion. The right renal pelvis (arrow) is prominent and normal size ureter is visible beneath it. (b) The upper right illustration shows a full kidney renogram obtained from the rectangular areas indicated on the upper left. A widened peak and delayed right-sided excretion is noted. After the renal cortex was flagged with a light pen (lower left), another renogram curve was generated (lower right). Note the correction of the right kidney curve to a normal pattern. This indicates that the cortical parenchyma is intact and if the outlet obstruction is corrected, the kidney should regain normal function. A partially occluding uretero-pelvic junction stricture was surgically corrected.

useful in evaluation of renal function in the presence of obstruction. The area of interest renogram after cortical 'flagging' also may accomplish a similar purpose (zum Winkel et al., 1972) (Fig. 4).

\section{The chlormerodrin uptake curve}

Immediately following the administration of ${ }^{197} \mathrm{Hg}$ chlormerodrin there is an immediate rise in count rate over both kidneys followed by a more gradual rise over the next $2-3 \mathrm{hr}$ due to accumulation and retention of the radiopharmaceutical by the tubular cells (Reba, McAfee \& Wagner, 1963; McAfee, Reba $\&$ Chodos, 1967). The rate of uptake is dependent on effective renal blood flow. Interpretation is based on the ratio of right to left kidney at various times, over the ratio at $5 \mathrm{~min}$. The normal range is $0.85-1.09$ at $30 \mathrm{~min} ; 0 \cdot 86-1 \cdot 10$ at $40-50 \mathrm{~min}$ and $0 \cdot 87-1 \cdot 11$ at 60 min (Fig. 5).

This test is rather time consuming and is not particularly popular at this time. It is not useful in delineating an abnormality when both kidneys are abnormal.

\section{Determination of renal function by clearances}

The agent of choice for determination of effective renal plasma flow is ${ }^{131}$ I orthoiodohippuric acid (Hippuran). The measurement of its disappearance from the plasma correlates closely with paraminohippuric acid (PAH) and the extraction efficiency of Hippuran from the plasma by the kidney is such that the clearance is a measure of effective renal plasma flow. Several methods have been developed for the measurement of the clearance of Hippuran so that it can be used as a clinical tool (Gott et al., 1962; Tauxe \& Hunt, 1966; Blaufox, Potchen \& Merrill, 1967; Razzak et al., 1968).

The classical method of measuring clearance used a constant infusion in order to maintain a level of plasma activity. By measuring urinary excretion over a specified period of time the clearance could be determined by the relationship $\mathrm{C}=[\mathrm{U}] \mathrm{V} /[\mathrm{P}] \mathrm{t}$ where $[\mathrm{U}] \mathrm{V}$ is the total amount excreted in the urine and [P] is plasma concentration. This method is not suitable for routine clinical use, since it requires an infusion and bladder catheterization for accuracy. 

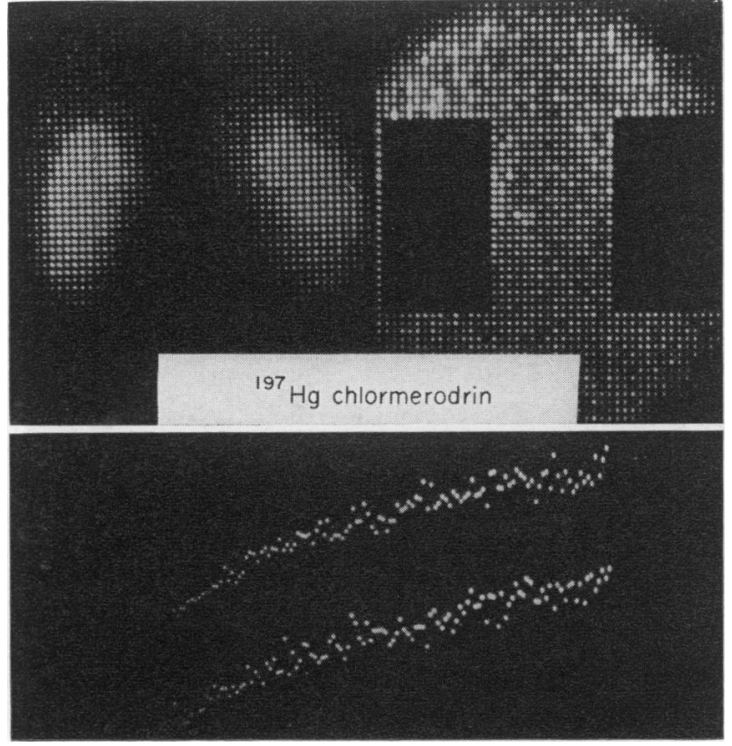

FIG. 5. Normal chlormerodrin accumulation study. Serial images were placed on magnetic tape at $15 \mathrm{sec}$ intervals after the administration of $100 \mu \mathrm{Ci}$ of ${ }^{197} \mathrm{Hg}$ chlormerodrin. At the completion of the study, the rectangular areas of interest shown at the upper right are selected and a time-activity curve is generated from these regions. The slope of uptake is symmetrical (see text for further explanation).

A variant on this method is a system of external monitoring of radioactivity and feedback of a signal which regulates the rate of infusion needed to maintain a constant plasma level (Christiansen, Hansen \& Madsen, 1970). With this system collection of urine is unnecessary. By knowing the concentration of the radioactivity in the infusing solution (Cs), the volume infused (Vs) in a period of time (T) and the plasma concentration (Cp), the clearance is equal to $\mathrm{Cs} \times \mathrm{Vs} / \mathrm{Cp} \times \mathrm{T}$.

More readily accessible to clinical use is the 'single shot' method of determining clearance (Sapirstein et al., 1955). While some controversy exists over the mathematical-physiological basis for computation of clearances after a single bolus injection of radioactivity, it has become a practical and acceptable way to determine effective renal plasma flow with radiohippuran and glomerular filtration rate with a variety of radiopharmaceuticals.

Determination of clearance with the single injection method has been carried out by several techniques, each seeking to further refine and simplify the determination. Serial blood samples can be obtained and the resultant curve plotted on semi-log paper. With Hippuran, a two-component curve is obtained which can be used to calculate clearance after determining the slopes and intercepts of the two components (Fig. 6).

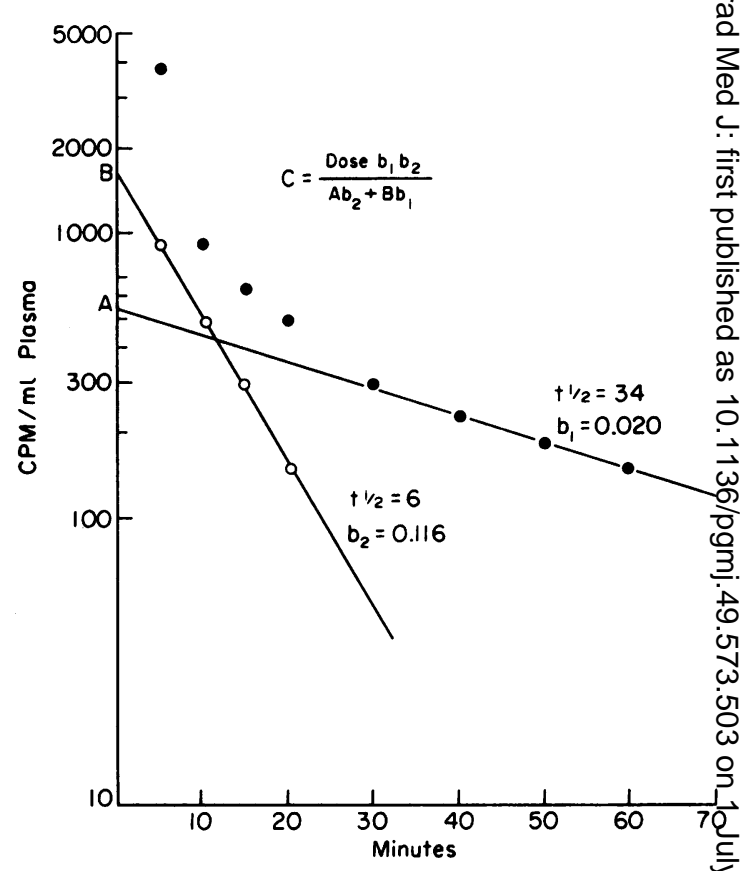

Fig. 6. Single injection hippuran clearance study. The disappearance of radioactivity after a single injection of $\vec{\varphi}$ ${ }^{131}$ I orthoiodohippurate is shown plotted on semilogarith $\omega \overrightarrow{ }$ mic graph paper. After about $\mathbf{4 0}$ min the points fall on straight line. A tangent to this line is drawn and extres. polated to time zero. Then the points on the line are subs tracted from the experimental data (closed circles). These points are fitted with a second straight line and the clearance $(C)$ is calculated from the slopes and intercepts 음 of the two lines as shown in the equation in the figure (reproduced by permission of M. D. Blaufox and L. M. $\vec{F}$ Freeman, Physicians Desk Reference for Radiology and $\overline{\mathrm{O}}$ Nuclear Medicine, 2nd edn. Litton Publications, Oradell, New Jersey).

External monitoring of a blood pool in the body can be substituted for multiple plasma samples. (Blaufox et al., 1967; Razzak et al., 1968). The curve can be related to actual plasma concentration b obtaining one or two plasma samples at stated times during the monitoring. Other simplified techniques use a limited number of plasma samples or a nomos gram relating urinary excretion at a specified time interval $(15 \mathrm{~min})$ to renalclearance (Taplin et al울. 1963).

Substances which are cleared solely by filtration through the glomerulus without metabolic degradae tion in the body and are not protein bound may bes used to measure glomerular filtration by their clear ance from the plasma. This is a useful and sensitive measure of renal function and many agents are now available which can be used for this determination in place of inulin. Probably the best of these are ${ }^{125}$ iothalamate (Malamos et al., 1967), ${ }^{169}$ Yb DTP (Hosain et al., 1969), and ${ }^{99 \mathrm{~m}}$ Tc DTPA (Hauser et al 

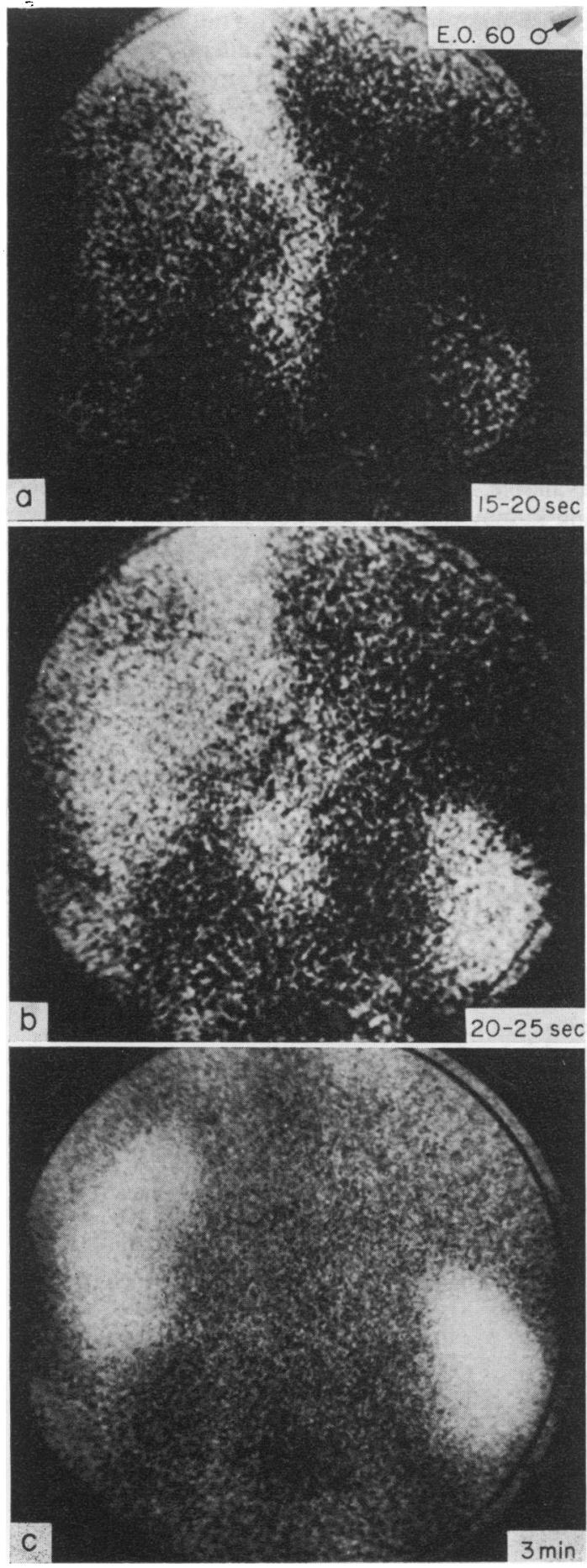

Fig. 7. Rapid sequential imaging with $99 \mathrm{~m}$ Tc DTPA. (a) 15-20 sec; (b) $20-25 \mathrm{sec}$; (c) $3 \mathrm{~min}$. The patency of the aorta and renal vascular structures is demonstrated.
1970). The ${ }^{25}$ I iothalamate is commercially available and has a good shelf life but is not readily used with external monitoring techniques due to the very low gamma energy of $27 \cdot 5-35.5 \mathrm{keV}$. The ytterbium chelate also had a good shelf life ( 31.8 days), and a high ratio of usable photons. The general availability of ${ }^{99 \mathrm{~m}} \mathrm{Tc}$, the development of a simple kit for preparation of the chelate and the very favourable physical characteristics of this radionuclide probably make ${ }^{99 \mathrm{~m}}$ Tc DTPA the agent of choice. With proper equipment it is possible to combine a determination of glomerular filtration rate with a vascular flow study, renal imaging and a renogram-type dynamic function test (Fig. 7).

One method of determining the clearance of ${ }^{99 \mathrm{~m}} \mathrm{Tc}$ DTPA utilizes three plasma samples at $2 \frac{1}{2}, 3$ and $3 \frac{1}{2}$ hr after administration of the radiopharmaceutical and fractional urine collection throughout this period. By $2 \frac{1}{2} \mathrm{hr}$ an equilibrium state has been achieved and the radioactivity of three plasma samples should fall on a straight line when plotted on semi-logarithmic paper. The slope of this line is determined by dividing 0.693 by the half-time of the disappearance of radioactivity. Because the distribution of ${ }^{99 \mathrm{~m}}$ Tc DTPA is the extracellular space the change in plasma concentration at this time is due only to urinary excretion. The volume of extracellular fluid is then determined by dividing the radioactivity excreted in a given period of time by the change in plasma concentration. The clearance is the extracellular volume multiplied by the slope of the plasma disappearance curve (Fig. 8).

\section{Renal imaging}

Highly accurate radiographic methods are available for the investigation of renal disease. The degree of resolution obtainable with X-rays and the specificity of the renal arteriogram provide anatomic information that cannot be duplicated with radionuclide techniques. On the other hand, the nuclear medical study is simple to perform, carries with it little risk or morbidity and can provide functional information otherwise not readily obtainable. The radionuclide and radiographic procedures are complementary to one another. More recently ultrasonic examination has come to be used with increasing frequency and also is complementary to studies performed with radionuclides.

The radionuclide image can provide information concerning renal size and functioning renal parenchyma. Overlying faecal and gas shadows, which can

FIG. 7 continued

An aortic aneurysm is present below the renal arteries. The kidneys appear normal on the static image obtained at about 3 min after injection and prior to concentration of radioactivity in the renal pelvis. 


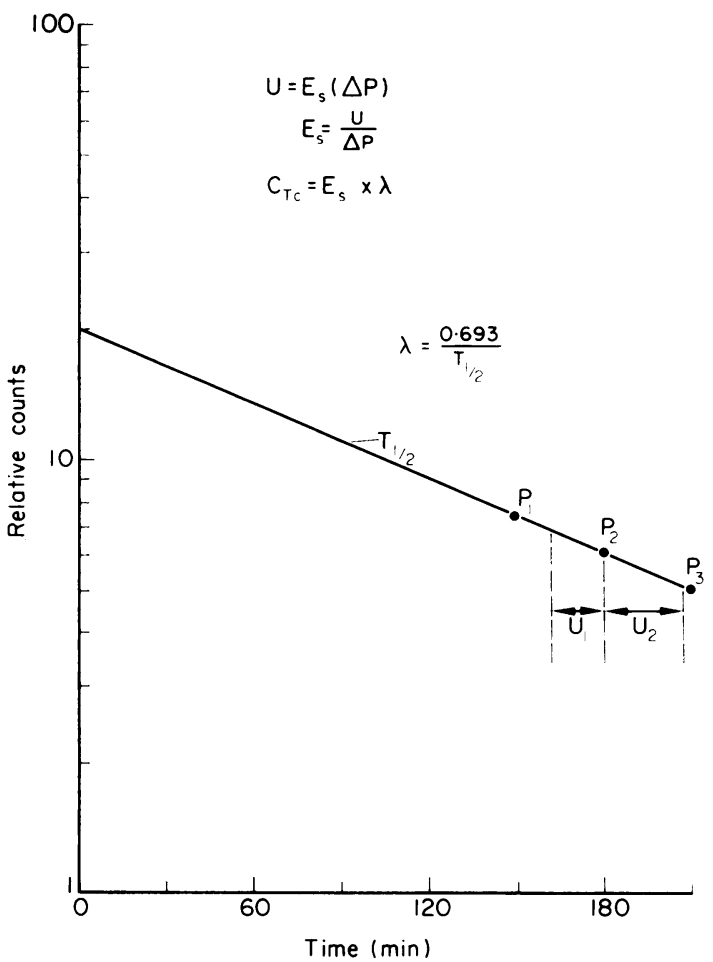

FIG. 8. Method of determining renal clearance of ${ }^{99 \mathrm{~m}} \mathrm{Tc}$ DTPA. See text for description. be problems in radiography, do not interfere with the renal scan. Patients who are allergic to the organic iodides used in urography and angiography are primeo candidates for radionuclide renal imaging studies. $\bar{c}$ The presence of functioning renal tissue can be determined in areas of ectopia and horseshoe kidney (Fig. 9). Localization for biopsy purposes can be accomplished with this method (Gottschalk, 1967), although ultrasound will probably replace radio-क्ष nuclidic methods for this purpose.

Imaging with radiohippuran is especially usefuifs when one kidney is not visualized in the intravenous $\overrightarrow{0}$ pyelogram. In cases of impaired function late images $\overrightarrow{-}$ (perhaps up to $4 \mathrm{hr}$ ) may reveal the presence of a kidney not detected at an earlier time. Since radio=-o hippuran is the most sensitive renal specific agent available, it may provide useful information concern-: ing kidney size and function in patients with severec renal insufficiency (Freeman et al., 1969a). Blood $c$ urea nitrogen levels and plasma creatinine levels over $100 \mathrm{mg} \%$ and $5 \mathrm{mg} \%$, respectively, provide little ${ }_{\mathrm{C}}^{O}$ obstacle to radiohippuran imaging. Attempts ato conventional intravenous urography and ${ }^{197} \mathrm{Hg}_{\triangle}$ chloromerodrin scintigraphy generally are unsuccess- ful at these levels of azotaemia.

An occasional space-occupying disease may be $\vec{\bullet}$ revealed by the radionuclide image when not seen ${ }^{\circ} n_{\omega}$ the radiograph. This will happen when the lesions situated so that no distortion of the calyceal syst occurs. Usually, however, radiographic techniquess are more definitive. With the present availability of

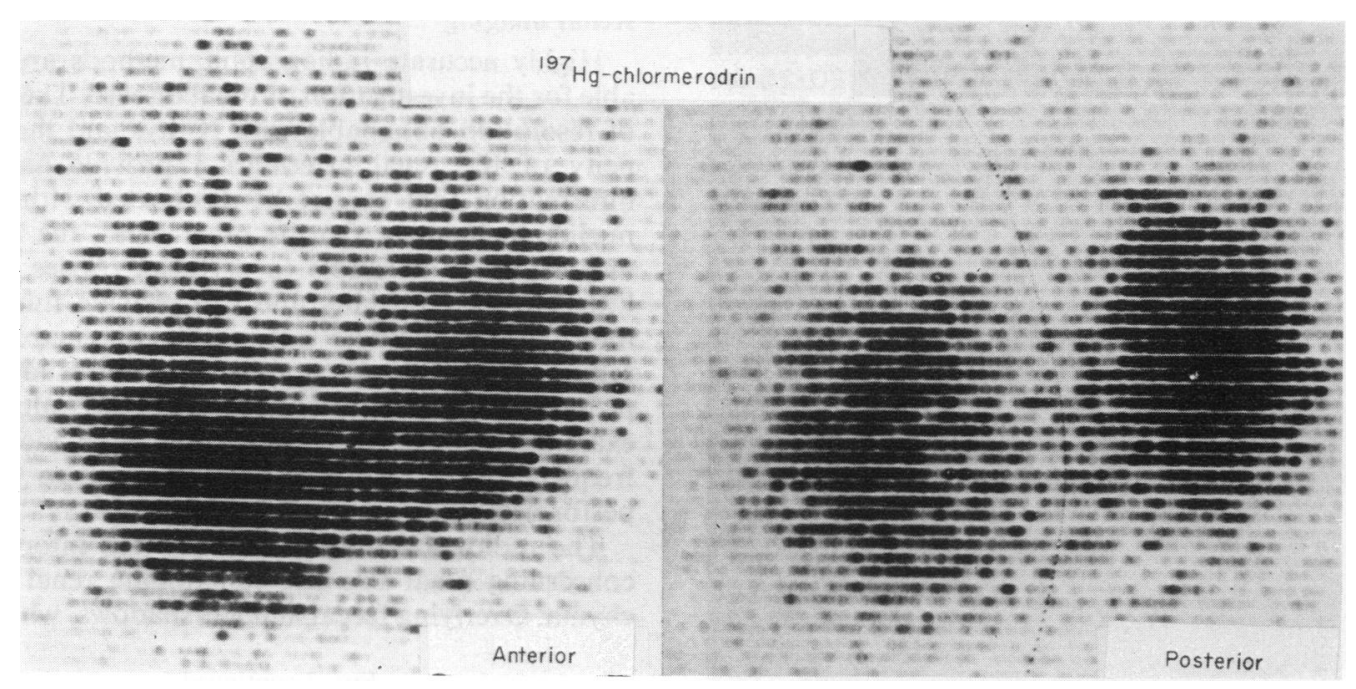

FIG. 9. Renal scan in horseshoe kidney. Conventional posterior scan on right shows poor activity in the region of the isthmus. The low energy gamma photons of ${ }^{187} \mathrm{Hg}$ are attenuated by the spine. The anterior scan on the left established the fact that the isthmus contains functioning parenchyma and is not merely joined by a fibrous bridge as might have been suspected by the posterior study alone. 


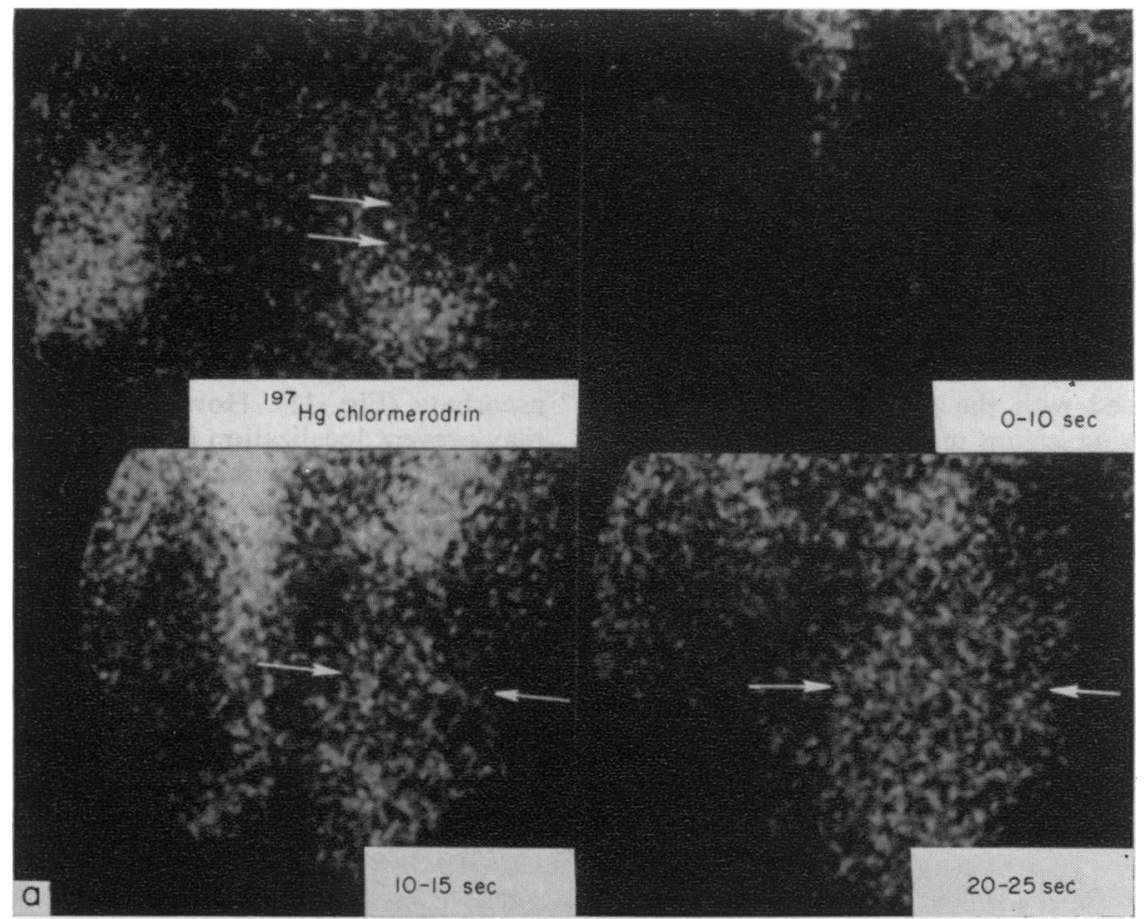

FIG. 10. Right kidney tumour. (a) Static posterior scintiphoto reveals a large area of absent activity in the upper half of the right kidney (double arrow). Sequential scintiphotos after a rapid intravenous bolus of ${ }^{90 \mathrm{~m}} \mathrm{Tc}$ pertechnetate show the filling of the aorta and, subsequently, an abundance of activity in the region of the defect seen on the radiochlormerodrin study (opposing arrows). This indicates the presence of a large vascular mass; most likely a neoplasm. The patient was moved prior to the start of the dynamic study to allow better centring of the area to be studied. (b) Renal angiogram confirms the presence of a large vascular neoplasm in the right kidney. The X-ray is oriented in a posterior-anterior position to allow easy comparison with the scintiphotos (courtesy of Dr Robert G. Bernstein). 
radiopharmaceuticals which may be administered with high levels of radioactivity and instrumentation which can provide rapid sequential imaging further assessment of space-occupying disease can be carried out in the Nuclear Medicine department. This can be particularly important in elderly, debilitated patients or in those who have an allergy to iodine containing organic contrast agents.

The use of a double-label study in the imaging of space-occupying disease is useful. The kidneys can be imaged first with ${ }^{197} \mathrm{Hg}$ chlormerodrin. Oblique views, readily obtained with the gamma camera may be useful in showing lesions most clearly. The presence of the ${ }^{197} \mathrm{Hg}$ in the kidneys is helpful in positioning the patient for the vascular study with ${ }^{99 \mathrm{~m}} \mathrm{Tc}$ pertechnetate or DTPA (Fig. 10). Setting the spectrometer at $140 \mathrm{keV}$ effectively eliminates any background from the ${ }^{197} \mathrm{Hg}$ present and rapid sequential images follow- ing the injection of a 10-15 mCi bolus of the technetium compound will reveal if the lesion is grossly 3 vascular or avascular with a high degree of reliability $\stackrel{\oplus}{\varrho}$ (Black et al., 1968; Freeman et al., 1969b).

Assessment of the patency of major renal vascular $\vec{\Rightarrow}$ structures or of segmented areas of the kidney is $\stackrel{?}{?}$ another useful procedure performed with radio- $\frac{}{5}$ nuclides. The presence of a renal image with any of $\frac{\overline{\bar{N}}}{\overline{0}}$. the agents used indicates a patent vascular supply. $\frac{\widehat{D}}{\widetilde{\phi}}$ Segmental infarctions are best seen with images $\varnothing$ obtained through the use of ${ }^{197} \mathrm{Hg}$ or ${ }^{99 \mathrm{~m}} \mathrm{Tc}$ iron ${ }^{2} \%$ ascorbate (Fig. 11). However, 'reflex' mechanisms $\vec{\circ}$

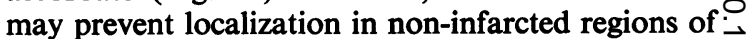
the kidney. The dynamic flow study with one of the $\vec{\omega}$ technetium-labelled compounds is probably the most $\stackrel{\odot}{\circ}$ suitable examination in this situation (Freeman et al., 1971). If the kidney is seen, no additional studies are $\underline{3}$. needed. If it fails to visualize, a radiohippuran $\overrightarrow{0}$

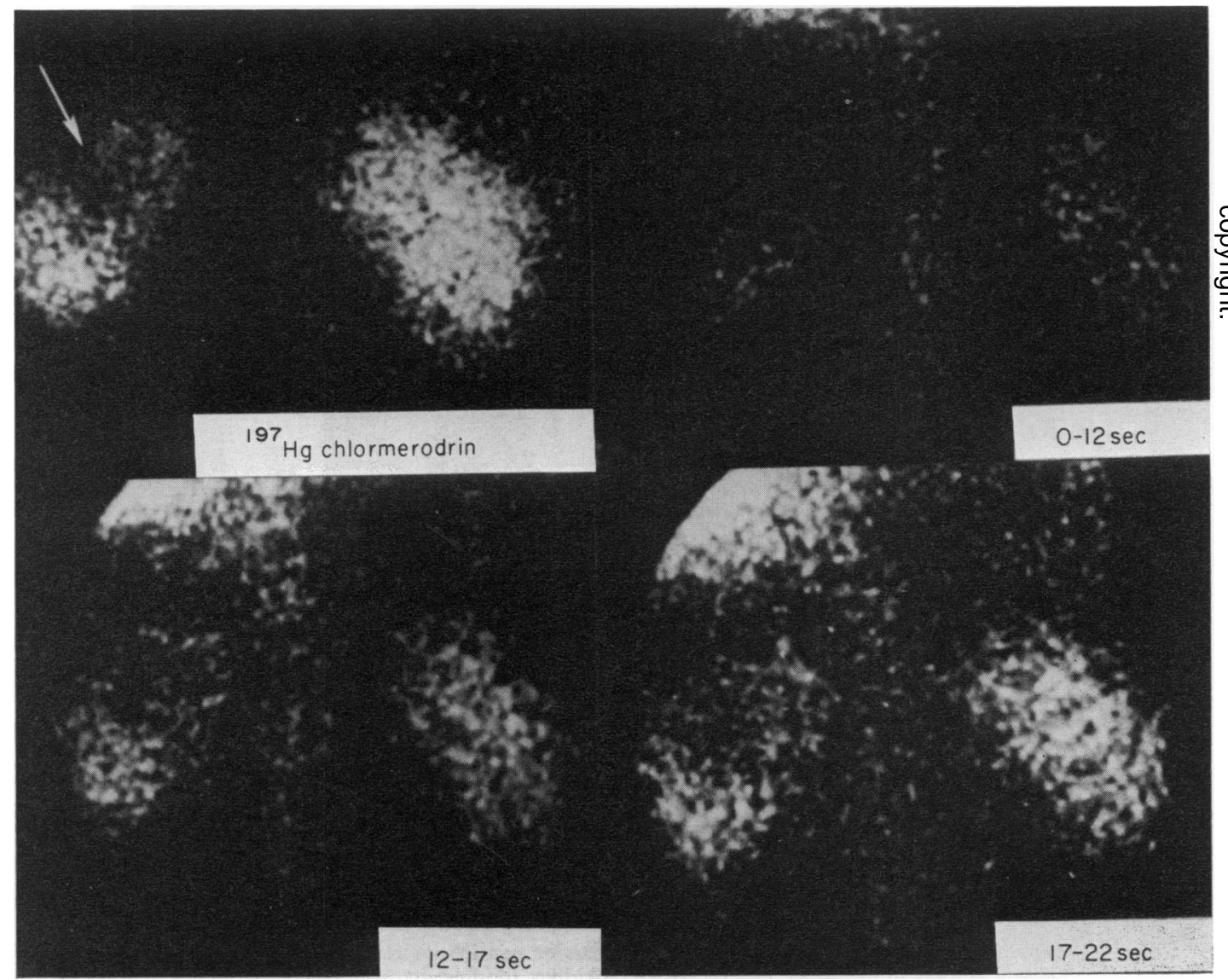

FIG. 11. Imaging studies in renal infarction after trauma. Static posterior scintiphoto several months after a stab wound of the left flank shows a focal area of absent activity in the upper portion of the left kidney (arrow). Sequential ${ }^{\circ 9 \mathrm{~m} T c}$ pertechnetate scintiphotos indicate the avascular nature of the lesion. Subsequent angiography confirmed the presence of a segmental infarct. 



FIG. 12. Imaging studies in the evaluation of renal transplants. (a) 2 days following a transplant, urine production was quite poor. Sequential anterior ${ }^{\circ \mathrm{m}_{\mathrm{m}} \mathrm{Tc}}$ pertechnetate 'flow' study shows the femoral vessels (opposing arrows) and good vascularization of the new kidney located in the right iliac fossa (single arrows). This proves that the newly anastomosed vascular channels are patent. (b) Sequential anterior Hippuran scintiphotos show a slower than normal uptake, but good excretion into the bladder. This is typical of acute tubular necrosis which occurs frequently after transplantation. It is a good prognostic sign that generally indicates that kidney function will improve in the very near future. This patient's urinary output was markedly improved 2 days after this study. 
scintigram may be helpful. Failure to image the kidney with either agent is highly suspicious of vascular occlusion. Radiographic angiography may be required to identify the location of the clot.

Following renal transplantation the patency of vascular anastomoses can be readily ascertained by flow studies. Hippuran scintigraphy and renography can also be used for this purpose (Fig. 12). Excretion of the radiohippuran into the bladder in the first 20-30 min is a favourable prognostic sign.

Radionuclide techniques are useful in cases of renal $\stackrel{D}{2}$

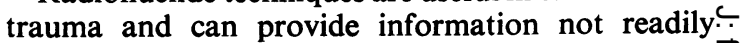
obtained from intravenous urography. Asymmetric $\vec{\equiv}$ vascularization and segmental ischaemic areas can be seen with chlormerodrin scans and the rapid: sequential scintiphotography with ${ }^{99} \mathrm{~m} \mathrm{Tc}$ (Freeman $\frac{\overline{\bar{N}}}{\overline{0}}$

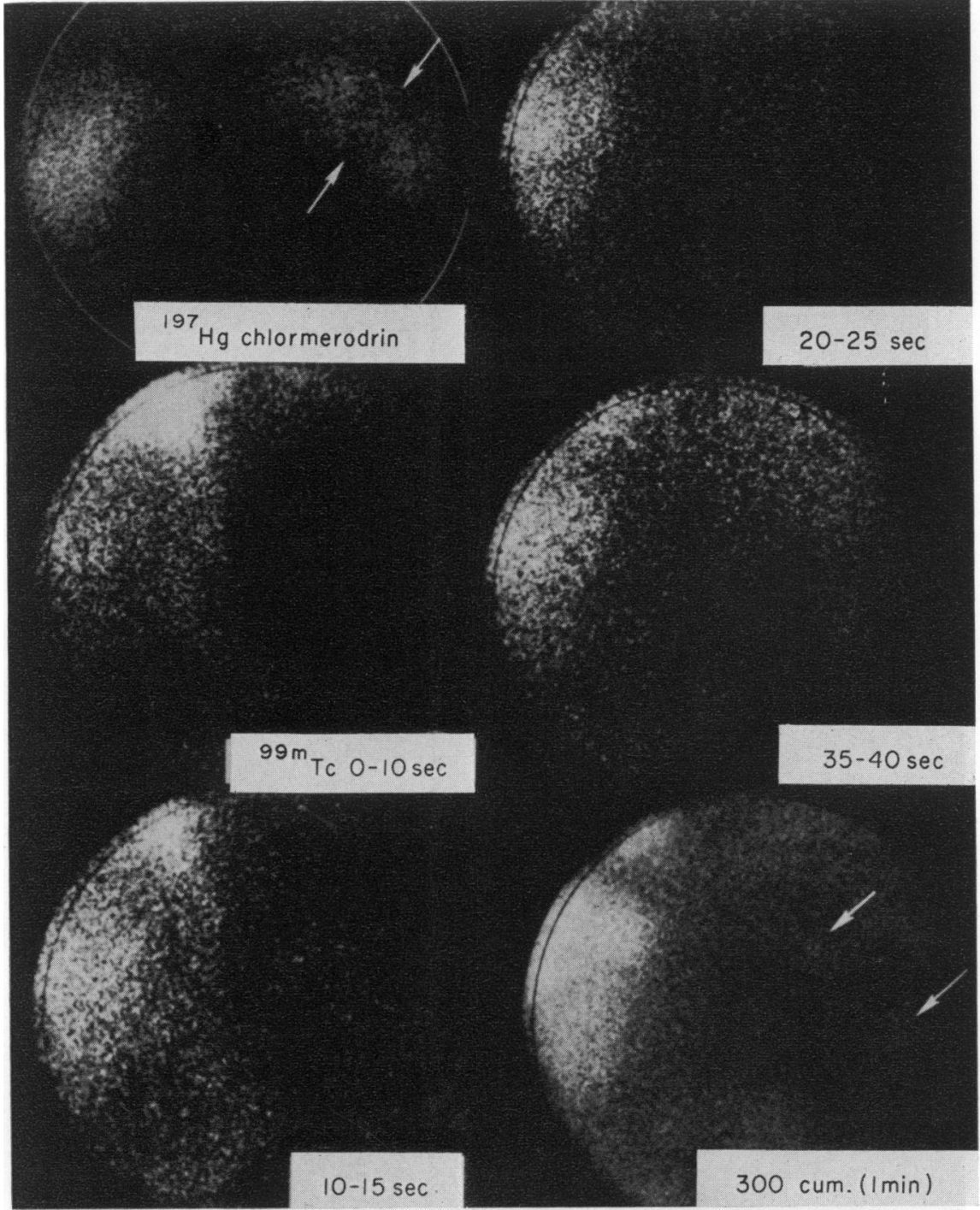

FIG. 13. Dynamic 'flow' study in renal hypertension (same patient as shown in Fig. 3). Static posterior scintiphotos show poor right-sided uptake of radiochlormerodrin with particularly impaired function in the middle portion of the kidney (opposing arrows). Sequential ${ }^{90 \mathrm{~m}} \mathrm{Tc}$ pertechnetate scintiphotos show very poor flow to the right kidney. A cumulative 300,000 count study at 1 min after injection shows some activity in the upper and lower poles of the right kidney with relative ischaemia in between (arrows). The left kidney appears normal. A renal artery stenosis was found at angiography (see Fig. 3b). 
et al., 1969b, 1971) (Fig. 13). The radionuclide studies are particularly useful for evaluation of the clinical course and assessment of the effect of therapeutic manoeuvres.

In renal hypertension the radionuclide image can help in demonstrating a difference in size of the two kidneys as well as the relative degree of vascular flow to each kidney. It is a useful adjunct to the renogram and can be performed together with the chlormerodrin uptake test. The accuracy of diagnosis of renal hypertension can be improved to about $95 \%$ of the cases when the combination of studies is performed (Meier \& Beierwaltes, 1966; McAfee et al., 1967; Burrows \& Farmelant, 1965).

\section{Vesicoureteral reflux}

In the investigation of congenital anomalies of the urinary tract and urinary infections in childhood, the demonstration of vesicoureteral reflux is extremely useful. Radiographic methods result in a high radiation dose and incomplete information. Reflux can optimally be studied by instillation of radioactive material in the bladder and constant monitoring of the urinary tract by means of a camera imaging device (Blaufox et al., 1971; Conway et al., 1972). The volume at which reflux occurs can readily be noted and the radiation dose is only several millirads.

\section{Future possibilities}

One of the newer radionuclides, ${ }^{123}$ iodine, may become available in sufficient quantity and at low enough cost that it will be in general use as a labelling agent. This will probably come about through the use of a new generation of proton accelerators at a number of locations in the world. Hippuran labelled with ${ }^{123}$ iodine would be extremely useful for renography combined with scintigraphy (Wellman et al., 1971). The $159 \mathrm{keV}$ gamma emission is much more efficiently collimated and detected than the $364 \mathrm{keV}$ principal gamma emission of ${ }^{131}$ iodine. The quality of images would be greatly enhanced.

It is hoped that some standardization of renography can be agreed upon in the future. This will make the examination of considerably greater value and probably would establish more quantitative criteria for interpretation.

Improvement in instrumentation is to be expected. Greater data handling capacity, improved spatial resolution and ease of readout are some desirable features which should be put into newer equipment.

There is considerable emphasis at this time on the development of cyclotron produced nuclides. These are generally of short half-life and many are positron emitters. It may be possible to use very high levels of activity for rapid sequential imaging in specific clinical diagnostic problems. However, optimum use will require advances in instrumentation as well.

\section{Acknowledgments}

Research supported in part by the United States Atomic Energy Commission.

\section{References}

ANGER, H.O. (1967) Radioisotope cameras. In: Instrumentation in Nuclear Medicine (Ed. by G. Hine), p. 495. Academic Press, New York.

BENDER, M.A. (1964) The digital autofluoroscope. In: Medical Radioisotope Scanning, vol. 1, p. 391. International Atomic Energy Agency, Vienna.

Black, M.D., King, C.D. \& Smith, D.R. (1968) Double isotope scintigraphy for differentiating between renal cysts and renal tumours. Journal of Urology, 98, 728.

Blaufox, M.D. (1972) Evaluation of renal function and disease with radionuclides. Progress in Nuclear Medicine, vol. 2. Karger, Basel.

Blaufox, M.D. \& Funk-Bretano, J-L. (1972) Radionuclides in Nephrology, Proceedings of an International Symposium. Grune and Stratton, New York.

Blaufox, M.D. \& Conroy, M.F. (1968) Measurement of renal mean transit time of Hippuran ${ }^{131} \mathbf{I}$ with external counting. Journal of Nuclear Biology and Medicine, 12, 107.

Blaufox, M.D., Gruskin, A., Sandler. P., Ogwo, J., Goldman, H. \& Edelman, C. JR (1971) Radionuclide scintiphotography for the detection of vesicoureteral reflux in children. Journal of Pediatrics, 79, 239.

Blaufox, M.D., Potchen, E.J. \& Merrill, J.P. (1967) Measurement of effective renal plasma flow in man by external counting methods. Journal of Nuclear Medicine, 8, 77.

Britton, K.E. \& Brown, N.J.G. (1971) The value in obstructive nephropathy of the hippuran output curve derived by computer analysis of the renogram. In: Dynamic Studies with Radioisotopes in Medicine, p. 274. International Atomic Energy Agency, Vienna.

Brown, N.G.J. \& Britton, K.E. (1972) The theory of renography and analysis of results. In: Radionuclides in Nephrology (Ed. by M. D. Blaufox and J-L. FunkBrentano), p. 315. Grune and Stratton, New York.

Burrows, B.A. \& Farmelant, M.H. (1965) The use of radioactive isotopes in the diagnosis of hypertension. Progress in Cardiovascular Disease, 8, 159.

Christiansen, N., Hansen, H. \& Madsen, P.O. (1970) Renal isotope clearance by external monitoring and feedback technique. A new catheter-free clearance method. Journal of Urology, 104, 26.

COE, F. \& Burke, G. (1965) Renal transit time: its measurement by the ${ }^{131}$ I Hippuran renogram. Journal of Nuclear Medicine, 6, 269.

Conway, J.J., King, L.R., Belman, A.B. \& Thorson, T. JR (1972) Detection of vesicoureteral reflux with radionuclide cystography; a comparison study with roentgenographic cystography. American Journal of Roentgenology (Radium Therapy and Nuclear Medicine, 115, 720.

Dynamic Studies with Radioisotopes in Medicine (1970) Proceedings of a Symposium, Rotterdam, 31 August4 September 1970. International Atomic Energy Agency, Vienna.

ECKelman, W. \& Richards, P. (1970) Instant ${ }^{\circ 9 m}$ Tc DTPA. Journal of Nuclear Medicine, 11, 761.

Freeman, L.M., Goldman, S.M., Shaw, R.K. \& Blaufox, M.D. (1969a) Kidney visualization with ${ }^{131}$ I ortho-iodohippurate in patients with renal insufficiency. Journal of Nuclear Medicine, 10, 545.

Freeman, L.M., Meng, C-H., Bernstein, R.G. \& Blaufox M.D. (1969b) Rapid sequential renal blood flow scintiphotography. Radiology, 92, 918. 
Freeman, L.M., Meng, C-H., Richter, M.W. \& Blaufox, M.D. (1971) Patency of major renal vascular pathways demonstrated by rapid blood flow scintiphotography. Journal of Urology, 105, 473.

GotT, F.S., Pritchard, W.H., Young, W.R. \& McINTYRE, W.J. (1962) Renal blood flow measurements from the disappearance of intravenously injected Hippuran. Journal of Nuclear Medicine, 2, 480.

GotTsChALK, A. (1967) Renal scanning. Journal of the American Medical Association, 202, 221.

Harbert, J.C., Ashburn, W.L. \& Davidson, J.D. (1968) An improved method of renography using the split crystal scintillation camera. Journal of Urology, 99, 681.

HARPER, P.V., LAThrop, K.A., HinN, G.M. et al. (1966) Technetium-99m-iron complex. In: Radioactive Pharmaceuticals (Ed. by G. A. Andrews, R. M. Kniseley and H. N. Wagner), p. 347. U.S. A.E.C., Division of Technical Information.

Hauser, W., Atkins, H.L., Nelson, K.G. \& Richard, P. (1970) Technetium-99m DTPA : a new radiopharmaceutical for brain and kidney scanning. Radiology, 94, 679.

Hauser, W., Atkins, H.L. \& Richards, P. Renal uptake of ${ }^{90 m}$ Tc-iron-ascorbic acid complex in man. Radiology, 101, 637.

Hirakawa, A., Kuwahara, M. \& Ueyama, H. (1972) Analog computer-aided RI renogram diagnosis. In: Radionuclides in Nephrology (Ed. by M. D. Blaufox and J-L. Funk-Brentano), p. 303. Grune and Stratton, New York.

Hosain, F., Reba, R.C. \& WAGNer, H.N. JR (1969) Measurement of glomerular filtration rate using chelated ytterbium169. Journal of Applied Radiation and Isotopes, 20, 517.

KaPlowitz, J.M., Mitchell, J.F. \& BlaHD, W.H. (1965) The radioisotope renogram. A comparison of qualitative and quantitative interpretation. Journal of the American Medical Association, 192, 90.

Lebowitz, E., Atkins, H.L., Hauser, W., Klopper, J.F., MuRANDA, M. \& Richards P. ${ }^{\circ m}$ Tc gelatin: a 'compound' with high renal specificity. Journal of Applied Radiation and Isotopes, 22, 786.

Lin, M.S., Weber, P.M., Winchell, H.S. \& KatchalskyKATZIR, A. (1972) Renal imaging in humans with the technetium-labeled polypeptide, caseidin.Journal of Nuclear Medicine, 13, 517.

MCAfee, J.G. (1970) Problems in evaluating the radiation dose for radionuclides excreted by the kidneys. In: Medical Radionuclides: Radiation Dose and Effects (Ed. by R. J. Cloutier, C. L. Edwards and W. S. Snyder), p. 270. U.S.A.E.C., Division of Technical Information.

MCAfEe, J.G., RebA, R.C. \& Chodos, R.B. (1967) Radioisotope methods in the diagnosis of renal vascular disease: a critical review. Seminars in Roentgenology, 2, 198.

Malamos, B., DontaS, A.S., KoutraS, D.A. et al. (1967) ${ }^{125}$ I sodium iothalamate in the determination of the glomerular filtration rate. Nuclear Medicine, 6, 304.

MaXwell, M.H., Lupu, A.N. \& Taplin, G.V. (1968) Radioisotope renogram in renal arterial hypertension. Journal of Urology, 100, 376.

Medical Radioisotope Scintigraphy (1969) Proceedings of a Symposium, Salzburg 6-15 August 1968. International Atomic Energy Agency, Vienna.

MeIER, D.A. \& Beierwaltes, W.H. (1966) Radioisotope renal studies and renal hypertension. A comparison of the sodium iodohippurate ${ }^{131}$ I renogram, chlormerodrin ${ }^{192} \mathrm{Hg}$ uptake, and renal scan. Journal of the American Medical Association, 198, 1257.
NelP, W.B., WAGNeR, H.N. JR \& ReBA, R.C. (1964) Renal 气 excretion of vitamin $B_{12}$ and its use in measurement of $>$ glomerular filtration rate in man. Journal of Laboratory and $\mathbb{D}$ Clinical Medicine, 63, 480.

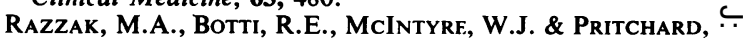
W.H. (1968) Determination of renal blood flow by external $\vec{F}$ monitoring of radiohippuran disappearance. Journal of $\mathcal{S}$ Urology, 100, 209.

Reba, R.C., Hosain, F. \& WAGNer, H.N. JR (1968) Indium$113 \mathrm{~m}$ diethylenetriaminepentaacetic acid (DTPA): a new $\overline{\bar{c}}$ radiopharmaceutical for study of the kidneys. Radiology, 90, 147.

Reba, R.C., McAfee, J.G. \& Wagner, H.N. JR (1963) ڤ Radiomercury-labelled chlormerodrin for in vivo uptake studies and scintillation scanning of unilateral renal lesions $\overrightarrow{0}$ associated with hypertension. Medicine, 42, 269.

Rosen, S.M., Hollenberg, N.K., Dealy, J.B. JR \& Merrill, J.P. (1968) Measurement of the distribution of blood flow in the human kidney using the intraarterial injection of ${ }^{133}$ Xe. Relationship to function in the normal and trans- $\exists$ planted kidney. Clinical Science, 34, 287.

Rosenthall, L. (1966) Radionuclide diagnosis of renal cysts and neoplasms using the gamma-ray scintillation camera: preliminary work. Journal of the Canadian Association of Radiologists, 17, 85.

Sapirstein, L.A., Vidt, D.G., Mandel, M.J. \& Hanusek, G. C (1955) Volumes of distribution and clearance of intra- 은 venously injected creatinine in the dog. American Journal $\rightarrow$ of Physiology, 181, 330.

Sigman, E.M., Elwood, C., Reagan, M.E., Morris, A.M. \& Catanzaro, A. (1965) The renal clearance of ${ }^{131} \mathrm{I}$ labeled sodium iothalamate in man. Investigative Urologe, $\vec{\varphi}$ 2, 432.

StaCY, B.D. \& ThorburN, G.D. (1966) Chromiumethylenediaminetetra-acetate for estimation of glomerulö: filtration rate. Science, 152, 1076.

StewarT, B.H. \& HAYNIE. T.P. (1962) Critical appraisal of the renogram in renal vascular disease. Journal of the American Medical Association, 180, 454.

TAPlin, G.V., Dore, E.K. \& Johnson, D.E. (1963) The quantitative radiorenogram for total and differential renal $\overline{\bar{O}}$ blood flow measurements. UCLA-514, June 1963.

TAUXE, W.N. \& HUNT, J.C. (1966) Evaluation of renal function by isotope techniques. Medical Clinics of North America, 50, 937.

Torrance, H.B., Davis, R.P. \& Clark, P. (1961) Detection of renal arterial stenosis in hypertension by the differential renal uptake of radioactive rubidium. Lancet, ii, 633 .

Turco, G.L., Ghemi, F. \& Segre, G. (1967) Quantitative 3 renography and appraisal of circulation of each kidney by means of compartmental analysis and the use of digital computers. In: Radioaktive Isotope in Klinik und Forschung (Ed. by K. Fellinger and R. Höfer), vol. 7, p. 129. Urban 윽 and Schwarzenberg, Munich.

Wellman, H.N., Berke, R.A., Robiins, P.J. \& ANGer, R.T $J_{R}$ (1971) Dynamic quantitative renal imaging with ${ }^{128} I-三$ hippuran. A possible salvation of the renogram. Journal of $\mathrm{N}$ Nuclear Medicine, 12, 405. Abstract.

zum Winkel, K., Jost, H., Motzkus, F., Venohr, H. \& N GoLDE, G. (1972) Dynamic and morphological examination $N$ with the scintillation camera and data processing. In: Radionuclides in Nephrology (Ed. by M. D. Blaufox and J-L. Funk-Brentano), p. 257. Grune and Stratton, Newco York. 